\title{
Main manometric findings and potential for anorectal physical therapy in the treatment of patients with evacuation disorders
}

\author{
Hugo Parra de CAMARGO, Vanessa Foresto MACHADO, Rogério Serafim PARRA, \\ Omar FÉRES, José Joaquim Ribeiro da ROCHA and Marley Ribeiro FEITOSA
}

Received: 4 May 2020

Accepted: 22 June 2020

\begin{abstract}
Background - Evacuation disorders are prevalent in the adult population, and a significant portion of cases may originate from pelvic floor muscle dysfunctions. Anorectal manometry (ARM) is an important diagnostic tool and can guide conservative treatment. Objective - To evaluate the prevalence of pelvic dysfunction in patients with evacuation disorders through clinical and manometric findings and to evaluate, using the same findings, whether there are published protocols that could be guided by anorectal manometry. Methods - A retrospective analysis of a prospective database of 278 anorectal manometries performed for the investigation of evacuation disorders in patients seen at the anorectal physiology outpatient clinic of Hospital das Clinicas da Faculdade de Medicina de Ribeirão Preto between January 2015 to June 2019 was conducted. The following parameters were calculated: resting pressure (RP), squeeze pressure (SP), high-pressure zone (HPZ), rectal sensitivity (RS) and rectal capacity (RC). The pressure measurements and manometric plots were reviewed to determine the diagnosis and to propose potential pelvic physical therapy procedures. Analysis of variance (ANOVA) and Fisher's exact test were used to compare the continuous variables and to evaluate the equality of variances between groups of patients with fecal incontinence (FI) and chronic constipation (CC). Results with a significance level lower than $0.05(P$-value $<0.05)$ were considered statistically significant. Statistical analysis was performed using IBM ${ }^{\circledR}$ SPSS ${ }^{\circledR}$ Statistics version 20 . Results - The mean age of the sample was $45 \pm 22$ years, with a predominance of females $(64.4 \%)$ and economically inactive $(72.7 \%)$ patients. The indications for exam performance were FI $(65.8 \%)$ and CC (34.2\%). Patients with FI had lower RP (41.9 mmHg x $67.6 \mathrm{mmHg} ; P<0.001)$, SP $(85.4 \mathrm{mmHg} \times 116.0 \mathrm{mmHg} ; P<0.001), \mathrm{HPZ}(1.49 \mathrm{~cm} \times 2.42$ $\mathrm{cm} ; P<0.001)$, RS $(57.9 \mathrm{~mL} \times 71.5 \mathrm{~mL} ; P=0.044)$ and RC $(146.2 \mathrm{~mL}$ x $195.5 \mathrm{~mL} ; P<0.001)$ compared to those of patients with CC. For patients with FI, the main diagnosis was the absence of a functional anal canal $(49.7 \%)$. For patients with CC, the main diagnosis was outflow tract obstruction (54.7\%). For patients with FI, the main protocol involved a combination of anorectal biofeedback (aBF) with tibial nerve stimulation (TNS) (57.9\%). For patients with CC, the most indicated protocol was aBF combined with TNS and rectal balloon training (RBT) (54.7\%). Conclusion - There was a high prevalence of pelvic floor changes in patients with evacuation disorders. There was a high potential for performing pelvic floor physical therapy based on the clinical and manometric findings.
\end{abstract}

HEADINGS - Fecal incontinence. Constipation. Pelvic floor. Manometry. Physical therapy specialty.

\section{INTRODUCTION}

Fecal incontinence (FI) and chronic constipation (CC) are evacuation disorders characterized by high frequency in general population and high impact on the quality of life of affected patients ${ }^{(1,2)}$. The prevalence of FI, characterized by the involuntary loss of fecal content, is reported to range from 2.2 to $20 \% \%^{(2)}$. Patients with CC may show heterogeneous symptoms (decreased evacuation frequency, defecation exertion, feeling of incomplete evacuation, fullness and hardened stools). It is estimated that the prevalence of CC in the adult population is $15 \%{ }^{(1)}$. There are groups with a higher risk of evacuation disorders, including the elderly, institutionalized individuals and individuals with a history of anorectal surgery or obstetric procedures. Some evacuation dysfunctions may be explained by changes in the pelvic muscu- lature ${ }^{(3)}$. For these cases, anorectal manometry (ARM) can assist in the differential diagnosis and treatment of patients ${ }^{(4)}$.

Anorectal changes may cause FI; in these cases, sphincter weakness and decreased rectal sensitivity or compliance are usually observed. Some individuals may also present with fecal retention and overflow incontinence, which are common in older individu$\mathrm{als}^{(2)}$. In turn, the participation of anorectal changes in the genesis of CC occurs through mechanisms of decreased propulsive force or increased resistance to fecal evacuation. However, the contribution of pelvic floor disorders to $\mathrm{CC}$ is not fully known due to their heterogeneity and to the multifactorial nature of $\mathrm{CC}^{(1)}$.

The treatment of evacuation disorders resulting from anorectal changes is complex and involves several specialties. Among the therapeutic modalities, pelvic floor physical therapy plays an important role in conservative rehabilitation. It can promote maintenance

Declared conflict of interest of all authors: none

Disclosure of funding: no funding received

Universidade de São Paulo, Faculdade de Medicina de Ribeirão Preto, Departamento de Cirurgia e Anatomia, Divisão de Coloproctologia, Ribeirão Preto, SP, Brasil.

Corresponding author: Hugo Parra de Camargo. E-mail: hugocparra@gmail.com 
or improvement of muscle strength and motor coordination, with positive effects on the quality of life of patients with anorectal disorders ${ }^{(5,6)}$. In addition to its low invasiveness, physical therapy is characterized by high acceptance and acceptable cost-effectiveness in the management of pelvic floor disorders ${ }^{(7)}$.

The Brazilian literature on the prevalence of anorectal dysfunction in patients with evacuation disorders is scarce, and little is known about the potential of pelvic physical therapy in outpatient clinics specialized in anorectal physiology. The objective of the present study was to evaluate the prevalence of pelvic dysfunction in patients with evacuation disorders through clinical and manometric analysis. In addition, the present study assesses whether clinical and manometric information can be used to propose physiotherapy protocols.

\section{METHODS}

A retrospective analysis was conducted of a prospective database of ARMs performed from January 2015 to June 2019. The exams were performed at Hospital das Clínicas da Faculdade de Medicina de Ribeirão Preto for the investigation of evacuation disorders. The exams were indicated by coloproctologists after clinical evaluation. The following exclusion criteria were included: incomplete medical records and tests performed without prior evaluation at the outpatient clinic for evacuation disorders. The study was approved by the institutional Research Ethics Committee (CAAE: 20119519.6.0000.5440).

To perform ARM, a Dynamed ${ }^{\circledR}$ device (São Paulo-SP, Brazil) was used, which has a 4.5-mm-diameter catheter, eight distilled water infusion channels and a central channel for inflating the rectal balloon. Three hours before the exam, the patients received an enema of $250 \mathrm{~mL}$ of $12 \%$ glycerin solution for rectal cleaning. The catheter was lubricated and inserted up to the middle-rectum, and measurements were performed every centimeter, starting at the seventh centimeter and ending at one centimeter from the anal edge. The following parameters were calculated in all patients: resting pressure (RP) (normal range: $40-70 \mathrm{mmHg}$ ), squeeze pressure (SP) (normal range: $100-180 \mathrm{mmHg}$ ), high-pressure zone (HPZ) (normal range: $2-3 \mathrm{~cm}$ in women and $2.5-3.5 \mathrm{~cm}$ in men), rectal sensitivity (RS) (normal range: $10-30 \mathrm{~mL}$ ) and rectal capacity (RC) (normal range, 100-250 $\mathrm{mL}$ ).

In all exams, the pressure measurements and the manometric plots were reviewed by two coloproctologists and a physical therapist, and the following manometric diagnoses were accepted for FI: absence of a functional anal canal, iatrogenic anal sphincter injury, voluntary contraction deficit, decreased rectal sensitivity and decreased rectal capacity. For CC, the following diagnoses were accepted: outflow obstruction, abdominal press deficit, decreased rectal sensitivity and paradoxical contraction.

Similarly, the pressure measurements and manometric plots were reviewed by two coloproctologists and two independent physical therapists, and the following protocols were proposed, either alone or in combination: anorectal biofeedback $(\mathrm{aBF})$, tibial nerve stimulation (TNS), and rectal balloon training (RBT).

Discrete variables are expressed as absolute values and percentages. Continuous variables are presented as measures of central tendency (mean or median). The Kolmogorov-Smirnov test was used to determine the normality of the distribution of the variables. Analysis of variance (ANOVA) and Fisher's exact test were used to compare continuous variables and assess the equality of variances between the groups of patients with FI and CC. Results with a significance level lower than $0.05(P$-value $<0.05)$ were considered statistically significant. Statistical analysis was performed using IBM $^{\circledR}$ SPSS $^{\circledR}$ Statistics version 20.

\section{RESULTS}

In the analyzed period, 278 ARMs were performed to investigate evacuation disorders. The mean age of the sample was $45 \pm 22$ years. There was a predominance of females $(64.4 \% ; n=179)$ and economically inactive $(72.7 \% ; \mathrm{n}=202)$ patients. The indications for exam performance were FI $(65.8 \%, n=183)$ and IC $(34.2 \%$; $n=95)$. The manometric measurements obtained are categorized and summarized in TABLE 1.

TABLE 1. Main manometric findings categorized in relation to normality.

\begin{tabular}{lcccccc}
\hline \multirow{2}{*}{$\begin{array}{l}\text { Manometric } \\
\text { findings }\end{array}$} & \multicolumn{2}{c}{$\begin{array}{c}\text { Below } \\
\text { normal }\end{array}$} & \multicolumn{2}{c}{ Normal } & \multicolumn{2}{c}{$\begin{array}{c}\text { Above } \\
\text { normal }\end{array}$} \\
\cline { 2 - 8 } & $\mathrm{n}$ & $\%$ & $\mathrm{n}$ & $\%$ & $\mathrm{n}$ & $\%$ \\
\hline RP (40-70 mmHg) & 103 & $37.0 \%$ & 107 & $38.5 \%$ & 68 & $24.5 \%$ \\
SP (100-180 mmHg) & 165 & $59.4 \%$ & 86 & $30.9 \%$ & 27 & $9.7 \%$ \\
HPZ (2-3.5 cm) & 131 & $47.1 \%$ & 116 & $41.7 \%$ & 31 & $11.2 \%$ \\
RS (10-30 mL) & 189 & $68.0 \%$ & 80 & $28.8 \%$ & 9 & $3.2 \%$ \\
RC (100-250 mL) & 66 & $23.7 \%$ & 171 & $61.5 \%$ & 41 & $14.8 \%$ \\
\hline
\end{tabular}

RP: resting pressure; SP: squeeze pressure; HPZ: high-pressure zone; RS: rectal sensitivity; RC: rectal capacity.

Patients with FI had lower RP, SP, HPZ, RS and RC than did patients with CC. The findings are provided in TABLE 2.

TABLE 2. Main manometric measures according to the clinical indication for manometry.

\begin{tabular}{|c|c|c|c|c|}
\hline $\begin{array}{l}\text { Manometric } \\
\text { findings }\end{array}$ & $\begin{array}{c}\text { All } \\
\text { patients }\end{array}$ & $\begin{array}{c}\text { Fecal } \\
\text { incontinence }\end{array}$ & $\begin{array}{c}\text { Chronic } \\
\text { constipation }\end{array}$ & $P$ value \\
\hline $\begin{array}{l}\mathrm{RP} \\
(\text { mean } \pm \mathrm{SD})\end{array}$ & $\begin{array}{c}50.7 \pm 28.0 \\
\mathrm{mmHg}\end{array}$ & $\begin{array}{c}41.9 \pm 23.2 \\
\mathrm{mmHg}\end{array}$ & $\begin{array}{c}67.6 \pm 28.8 \\
\mathrm{mmHg}\end{array}$ & $<0.001$ \\
\hline $\begin{array}{l}\text { SP } \\
(\text { mean } \pm S D)\end{array}$ & $\begin{array}{c}95.9 \pm 57.7 \\
\mathrm{mmHg}\end{array}$ & $\begin{array}{c}85.4 \pm 53.3 \\
\mathrm{mmHg}\end{array}$ & $\begin{array}{c}116.0 \pm 60.7 \\
\mathrm{mmHg}\end{array}$ & $<0.001$ \\
\hline $\begin{array}{l}\mathrm{HPZ} \\
(\text { mean } \pm \mathrm{SD})\end{array}$ & $\begin{array}{c}1.81 \pm 1.44 \\
\mathrm{~cm}\end{array}$ & $\begin{array}{c}1.49 \pm 1.44 \\
\mathrm{~cm}\end{array}$ & $\begin{array}{c}2.42 \pm 1.25 \\
\mathrm{~cm}\end{array}$ & $<0.001$ \\
\hline $\begin{array}{l}\text { RS } \\
(\text { mean } \pm S D)\end{array}$ & $\begin{array}{c}62.5 \pm 53.2 \\
\mathrm{~mL}\end{array}$ & $\begin{array}{c}57.9 \pm 47.9 \\
\mathrm{~mL}\end{array}$ & $\begin{array}{c}71.5 \pm 61.3 \\
\mathrm{~mL}\end{array}$ & 0.044 \\
\hline $\begin{array}{l}\mathrm{RC} \\
(\text { mean } \pm \mathrm{SD})\end{array}$ & $\begin{array}{c}163.1 \pm 95.6 \\
\mathrm{~mL}\end{array}$ & $\begin{array}{c}146.2 \pm 79.8 \\
\mathrm{~mL}\end{array}$ & $\begin{array}{c}195.5 \pm 113.9 \\
\mathrm{~mL}\end{array}$ & $<0.001$ \\
\hline
\end{tabular}

RP: resting pressure; SP: squeeze pressure; HPZ: high-pressure zone; RS: rectal sensitivity; RC: rectal capacity; SD: standard deviation.

For patients with FI, the main diagnosis was the absence of a functional anal canal $(49.7 \%, n=91)$. For patients with $C C$, the main diagnosis was outflow tract obstruction $(54.7 \%, \mathrm{n}=52)$. The diagnoses according to indication are provided in TABLE 3.

After analysis of the manometric findings, it was possible to propose an anorectal physical therapy protocol for most patients $(98 \% ; n=273)$. For patients with FI, the main protocol involved the combination of aBF with TNS $(57.9 \%, n=106)$. For patients with $\mathrm{CC}$, aBF combined with TNS and RBT $(54.7 \%, \mathrm{n}=52)$ was the most indicated protocol. TABLE 4 summarizes all physical therapy protocols according to exam indications. 
TABLE 3. Manometric diagnoses according to the clinical indication for manometry.

\begin{tabular}{lcclll}
\hline Fecal incontinence & \multicolumn{5}{l}{ Chronic constipation } \\
\hline $\begin{array}{l}\text { Absence of a } \\
\text { functional anal } \\
\text { canal }\end{array}$ & 91 & $49.7 \%$ & $\begin{array}{l}\text { Out flow } \\
\text { obstruction }\end{array}$ & 52 & $54.7 \%$ \\
$\begin{array}{l}\text { Decreased rectal } \\
\text { sensitivity }\end{array}$ & 55 & $30.1 \%$ & $\begin{array}{l}\text { Abdominal } \\
\text { press deficit }\end{array}$ & 22 & $23.2 \%$ \\
$\begin{array}{l}\text { Voluntary } \\
\text { contraction deficit }\end{array}$ & 15 & $8.2 \%$ & $\begin{array}{l}\text { Decreased rectal } \\
\text { sensitivity } \\
\text { Paradoxical }\end{array}$ & 13 & $13.7 \%$ \\
$\begin{array}{l}\text { Iatrogenic anal } \\
\text { sphincter injury }\end{array}$ & 12 & $6.6 \%$ & $6.3 \%$ \\
$\begin{array}{l}\text { Decreased rectal } \\
\text { capacity }\end{array}$ & 7 & $3.8 \%$ & Normal & 2 & $2.1 \%$ \\
Normal & 3 & $1.6 \%$ & & & \\
\hline
\end{tabular}

TABLE 4. Anorectal physiotherapy proposal according to the clinical indication for anal manometry.

\begin{tabular}{lcclcc}
\hline Fecal incontinence & & \multicolumn{5}{l}{ Chronic constipation } \\
\hline aBF+TNS & 106 & $57.9 \%$ & aBF+TNS+RBT & 52 & $54.7 \%$ \\
- & - & - & aBF+RBT & 28 & $29.5 \%$ \\
TNS & 74 & $40.4 \%$ & TNS & 13 & $13.7 \%$ \\
No proposal & 3 & $1.6 \%$ & No proposal & 2 & $2.1 \%$ \\
\hline
\end{tabular}

aBF: anorectal biofeedback; TNS: tibial nerve stimulation; RBT: rectal baloon training.

\section{DISCUSSION}

Our study demonstrated a high prevalence of manometric changes in patients with evacuation dysfunctions, which may be explained by selection because all patients were evaluated in a tertiary level outpatient coloproctology clinic and because the exam was indicated by a specialist and after clinical suspicion of anorectal dysfunction. Furthermore, it is known that anorectal dysfunction is common, especially in women and in older individuals, as in our sample ${ }^{(3)}$. ARM is an important tool that provides valuable physiopathologic information in patients with defecatory disorders. For FI, ARM is useful for assessing the strength of the anorectal musculature and rectal reservoir function ${ }^{(8)}$. In those cases of CC, ARM assesses dyssynergia of the abdominopelvic musculature, which can compromise defecatory propulsion ${ }^{(9)}$.

Regarding the manometric parameters evaluated, RP was calculated in the high-pressure zone of the anal canal during rest, after the stabilization period ${ }^{(10)}$. $\mathrm{RP}$ values between $40-70 \mathrm{mmHg}$ were considered normal ${ }^{(11)}$. As observed in our study, patients with FI had lower RP values, which may have contributed to fecal loss, especially in the presence of sphincter deficiency ${ }^{(12)}$. In those cases, $\mathrm{aBF}$ has a questionable benefit, since the RP is given by the smooth muscle tone of the internal sphincter, which is less susceptible to training through contractile stimuli. TNS, on the other hand, seems to have beneficial effects on the PR of patients with IF. In the study by Heywood et al, patients undergoing TNS showed a $6.8 \%$ increase in RP values, however without statistical significance, probably because of the small sample size and the short follow-up interval ${ }^{(13)}$.

$\mathrm{SP}$ is the highest pressure in the canal during maximal voluntary contraction. Values between $100-180 \mathrm{mmHg}$ were considered nor$\mathrm{mal}^{(11)}$. In patients with FI, SP is decreased, as demonstrated in the present study; however, there may be a weak correlation between manometric findings and FI severity ${ }^{(14,15)}$. In these cases, aBF has been used as a way to increase the capacity for contraction and/or improve sphincter motor coordination. In the study by Parker et al., the use of aBF, even for a short time, was responsible for strengthening sphincter muscles and beneficial for patients with $\mathrm{FI}^{(16)}$.

$\mathrm{HPZ}$ was defined as the length of the anal canal with pressures at least $30 \%$ higher than those found in the rectum. In asymptomatic patients, high HPZ values are observed ${ }^{(17)}$. In the present study, we found low HPZ more frequently, which may be explained by the high prevalence of patients with FI in the sample. In fact, when compared to patients diagnosed with CC, individuals with FI had significantly lower $\mathrm{HPZ}$ values. The real effect of aBF on $\mathrm{HPZ}$ needs further investigation, however, striated muscle fibers such as those seen in the external anal sphincter, levator ani and puborectalis may contribute to the pressures found in HPZ. Therefore, the benefit of aBF observed in individuals with FI can, in part, be explained by the stimulation of these muscle groups and the consequent tonus improvement in the high-pressure zone ${ }^{(18)}$.

In the present study, there was a high prevalence of rectal hyposensitivity. Hyposensitivity was higher in patients with CC; however, this decreased sensation may also be associated with episodes of $\mathrm{FI}^{(19)}$. Although rectal hyposensitivity is considered a poor predictor of response, $\mathrm{aBF}$ in patients with $\mathrm{CC}$ and rectal hyposensitivity may promote relaxation of the anorectal muscles, restoration of rectal sensitivity and clinical improvement ${ }^{(20)}$. Even in patients with $\mathrm{FI}, \mathrm{aBF}$ can provide training for the pelvic floor musculature, with improvements in RS, promotion of motor coordination and increased quality of life ${ }^{(21-24)}$. Rectal balloons may help in the diagnosis and management of $\mathrm{CC}$ due to anorectal dysfunction, and RBT, although apparently inferior to aBF, seems to contribute to improving the synergy of the pelvic muscles and decreasing chronic constipation symptoms ${ }^{(25,26)}$. However, the effect of RBT may be associated with muscle training itself; therefore, we chose to propose its combined use with aBF.

Regarding RC, most patients did not present changes. However, the main alteration found was decreased RC, especially in the group of patients with IF. Lower RC values may be associated with FI due to reservoir loss with fecal urgency ${ }^{(27)}$. There are few interventions aimed at correcting CR disorders. However, some studies have demonstrated significant benefits of aBF in patients with FI, which can be demonstrated by the decrease in fecal urgency episodes ${ }^{(16)}$.

To the best of our knowledge, this is the first study in our population to assess whether there is a possibility of establishing an anorectal physiotherapy protocol in patients with evacuation disorders at a specialized outpatient clinic. The high prevalence of anorectal disorders in these patients with evacuation disorders makes physiotherapy an interesting approach. The clinical evaluation of the patients added to a careful analysis of the manometric parameters allowed us to choose the physiotherapy protocols according to the best evidence in the literature. Therefore, the formation of a multidisciplinary pelvic floor team, can contribute to the clinical management of these conditions. Furthermore, the evidence points out that physical therapy assisted by a trained professional can significantly improve the quality of life in patients with evacuation disorders caused, even partially, by changes in the abdominopelvic muscles. The evidence for the use of the suggested protocols is relevant, however the choice of the type of intervention should always be carried out individually and shared with the patient ${ }^{(28,29)}$. In general, aBF, TNS and RBT, alone or in combination, have shown favorable results in the treatment of evacuation disorders, with low risk and good tolerance ${ }^{(30-35)}$. 
The present study has limitations that deserve mention. Because this is a retrospective analysis, some information may have been lost during data collection; however, by using a prospective database, this risk was minimized. Despite the existence of a potential benefit of physiotherapy protocols in the rehabilitation of patients with evacuatory disorders and pelvic floor dysfunction, the real role of physical therapy in our patients can't be demonstrated unless intervention studies are conducted, such investigation is already underway in our unit. However, it is known that physical therapy in multidisciplinary anorectal physiology units can assist in the prevention and treatment of evacuation disorders, in addition to promoting improvement in the quality of life of patients ${ }^{(22)}$.

\section{CONCLUSION}

There was a high prevalence of pelvic floor changes in patients with evacuation disorders. The detailed analysis of the clinical history and the measurements obtained by ARM can provide parameters for the construction of a pelvic floor physiotherapy protocol.

\section{Authors' contribution}

Camargo HP: study conception, data collection and manuscript writing. Machado VF, Parra RS, Féres O, Rocha JJR: study conception and manuscript review. Feitosa MR: study conception, manuscript writing, statistical analysis and manuscript review.

\section{Orcid}

Hugo Parra de Camargo: 0000-0001-7267-1880.

Vanessa Foresto Machado: 0000-0002-8644-5881.

Rogério Serafim Parra: 0000-0002-5566-9284.

Omar Féres: 0000-0003-3593-0526.

José Joaquim Ribeiro da Rocha: 0000-0001-7118-0545.

Marley Ribeiro Feitosa: 0000-0002-4440-2023.

Camargo HP, Machado VF, Parra RS, Féres O, Rocha JJR, Feitosa MR. Principais achados manométricos e potencial da fisioterapia anorretal no tratamento de pacientes com distúrbios evacuatórios. Arq Gastroenterol. 2020;57(3):306-10.

RESUMO - Contexto - Os distúrbios evacuatórios são prevalentes na população adulta e uma parcela significativa dos casos pode ter origem a partir de disfunções da musculatura do assoalho pélvico. A manometria anorretal (MAR) é importante ferramenta diagnóstica e pode guiar o tratamento conservador. Objetivo - Avaliar a prevalência de disfunção pélvica em pacientes com distúrbios de evacuação por meio de achados clínicos e manométricos e avaliar, usando os mesmos achados, se existem protocolos publicados que possam ser guiados pela MAR. Métodos - Conduziu-se uma análise retrospectiva de um banco de dados prospectivo de 278 manometrias anorretais realizadas para investigação de distúrbios evacuatórios em pacientes do ambulatório de fisiologia anorretal do Hospital das Clínicas da Faculdade de Medicina de Ribeirão Preto, de janeiro de 2015 a junho de 2019 . Os seguintes parâmetros foram calculados: pressão de repouso (RP), pressão de contração voluntária (PVC), canal anal funcional (CAF), sensibilidade retal (SR) e capacidade retal (CR). As medidas pressóricas e os gráficos manométricos foram revisados para elaboração do diagnóstico e para a proposição dos potenciais procedimentos de fisioterapia pélvica. Para comparação das variáveis contínuas e avaliação da igualdade entre variâncias, utilizou-se a análise de variância (ANOVA) e o teste exato de Fisher, entre os grupos de pacientes com incontinência fecal (IF) e constipação crônica (CC). Resultados com nível de significância menor que $0,05(P$-valor $<0,05)$ foram considerados estatisticamente relevantes. Para análise estatística utilizou-se o programa IBM ${ }^{\circledR}$ SPSS ${ }^{\circledR}$ Statistics, versão 20 . Resultados - A idade média dos pacientes foi de $45 \pm 22$ anos de idade, com predomínio do sexo feminino $(64,4 \%)$ e economicamente inativo $(72,7 \%)$. As indicações para a realização do exame foram IF $(65,8 \%)$ e CC $(34,2 \%)$. Pacientes com IF apresentaram menores valores de PR $(41,9 \mathrm{mmHg}$ x $67,6 \mathrm{mmHg} ; P<0,001)$, PCV $(85,4 \mathrm{mmHg} \times 116,0 \mathrm{mmHg} ; P<0,001) \mathrm{CAF}(1,49 \mathrm{~cm} \times 2,42$ $\mathrm{cm} ; P<0,001)$, SR $(57,9 \mathrm{~mL} \times 71,5 \mathrm{~mL} ; P=0,044)$ e CR $(146,2 \mathrm{~mL} \times 195,5 \mathrm{~mL} ; P<0,001)$, quando comparados aos pacientes com CC. Nos pacientes com IF, o principal diagnóstico foi de ausência de canal anal funcional (49,7\%). Em pacientes com CI, o principal diagnóstico foi de obstrução da via de saída (54,7\%). Para pacientes com IF, o principal protocolo foi a associação do biofeedback anorretal (BFa) com estimulação do nervo tibial (ENT) $(57,9 \%$ ). Já nos pacientes com CC, o protocolo mais indicado foi o de BFa associado à ENT e treinamento com balão retal (54,7\%). Conclusão - Observou-se elevada prevalência de alterações no assoalho pélvico de pacientes com distúrbios evacuatórios. Verificou-se elevado potencial para realização de fisioterapia do assoalho pélvico com base nos achados clínicos e manométricos.

DESCRITORES - Incontinência fecal. Constipação intestinal. Diafragma da pelve. Manometria. Fisioterapia.

\section{REFERENCES}

1. Bharucha AE, Lacy BE. Mechanisms, evaluation, and management of chronic constipation. Gastroenterology. 2020:158:1232-49.e3. doi:10.1053/j.gastro.2019.12.034.

2. Menees SB, Almario CV, Spiegel BMR, Chey WD. Prevalence of and factors associated with fecal incontinence: results from a population-based survey. Gastroenterology. 2018;154:1672-81.e3.

3. Rao SS, Bharucha AE, Chiarioni G, Felt-Bersma R, Knowles C, Malcolm A, et al. Functional anorectal disorders. Gastroenterology. 2016 :S0016-5085(16)00175-X. doi:10.1053/j.gastro.2016.02.009.

4. Seo M, Joo S, Jung KW, Song EM, Rao SSC, Myung SJ. New metrics in high-resolution and high-definition anorectal manometry. Curr Gastroenterol Rep. 2018;20:57.
5. Khera AJ, Chase JW, Salzberg M, Thompson AJV, Kamm MA. Gut-directed pelvic floor behavioral treatment for fecal incontinence and constipation in patients with inflammatory bowel disease. Inflamm Bowel Dis. 2019;25: 620-6.

6. Narayanan SP, Bharucha AE. A practical guide to biofeedback therapy for pelvic floor disorders. Curr Gastroenterol Rep. 2019;21:21.

7. Panman C, Wiegersma M, Kollen BJ, Berger MY, Lisman-Van Leeuwen Y, Vermeulen KM, et al. Two-year effects and cost-effectiveness of pelvic floor muscle training in mild pelvic organ prolapse: a randomised controlled trial in primary care. BJOG. 2017;124:511-20.

8. Ruiz NS, Kaiser AM. Fecal incontinence - challenges and solutions. World J Gastroenterol. 2017;23:11-24. 
9. Lalwani N, El Sayed RF, Kamath A, Lewis S, Arif H, Chernyak V. Imaging and clinical assessment of functional defecatory disorders with emphasis on defecography. Abdom Radiol (NY). 2019. doi:10.1007/s00261-019-02142-9.

10. Bordeianou LG, Carmichael JC, Paquette IM, Wexner S, Hull TL, Bernstein M, et al. Consensus statement of definitions for anorectal physiology testing and pelvic floor terminology (Revised). Dis Colon Rectum. 2018;61:421-7.

11. Papaconstantinou HT. Evaluation of anal incontinence: minimal approach, maximal effectiveness. Clin Colon Rectal Surg. 2005;18:9-16.

12. Bordeianou L, Lee KY, Rockwood T, Baxter NN, Lowry A, Mellgren A, et al. Anal resting pressures at manometry correlate with the fecal incontinence severity index and with presence of sphincter defects on ultrasound. Dis Colon Rectum. 2008;51:1010-4

13. Nick A. Heywood, James S. Pearson, James E. Nicholson, Clare Molyneux, Abhiram Sharma, Edward S. Kiff, et al. The short-term effects of posterior tibial nerve stimulation on anorectal physiology in patients with faecal incontinence: a single centre experience. Therap Adv Gastroenterol. 2018;11 1756284818786111 .

14. Kochi M, Egi H, Adachi T, Takakura Y, Mukai S, Taguchi K, et al. Preoperative incremental maximum squeeze pressure as a predictor of fecal incontinence after very low anterior resection for low rectal cancer. Surg Today. 2019. doi:10.1007/ s00595-019-01926-2.

15. Heitmann PT, Rabbitt P, Schloithe A, Patton V, Skuza PP, Wattchow DA, et al. Relationships between the results of anorectal investigations and symptom severity in patients with faecal incontinence. Int J Colorectal Dis. 2019;34: 1445-54.

16. Parker CH, Henry S, Liu LWC. Efficacy of Biofeedback Therapy in Clinical Practice for the Management of Chronic Constipation and Fecal Incontinence. J Can Assoc Gastroenterol. 2019;2:126-31.

17. Li Y, Yang X, Xu C, Zhang Y, Zhang X. Normal values and pressure morphology for three-dimensional high-resolution anorectal manometry of asymptomatic adults: a study in 110 subjects. Int J Colorectal Dis. 2013;28:1161-8.

18. S. Rattan and J. Singh. Basal internal anal sphincter tone, inhibitory neurotransmission, and other factors contributing to the maintenance of high pressures in the anal canal. Neurogastroenterol Motil. 2011;23:3-7.

19. Burgell RE, Bhan C, Lunniss PJ, Scott SM. Fecal incontinence in men: coexistent constipation and impact of rectal hyposensitivity. Dis Colon Rectum. 2012; $55: 18-25$.

20. Ahn JY, Myung SJ, Jung KW, Yang DH, Koo HS, Seo SY. Effect of biofeedback therapy in constipation according to rectal sensation. Gut Liver. 2013;7:157-62.

21. dos Santos KLAS, Cavenaghi S, Folchine AER, Carvalho LH, Martins P, Ferreir LL, et al. Effects of biofeedback in the treatment of female fecal incontinence J Coloproctology. 2018;38:194-8.
22. Ussing A, Dahn I, Due U, Sorensen M, Petersen J, Bandholm T. Efficacy of supervised pelvic floor muscle training and biofeedback vs attention-control treatmen in adults with fecal incontinence. Clin Gastroenterol Hepatol. 2019;17:2253-61.e4.

23. Malik K, Dua A. Biofeedback. In: StatPearls [Internet]. Treasure Island (FL) StatPearls Publishing; 2020. Available from: https://www.ncbi.nlm.nih.gov/books/ NBK553075/

24. Lee KH, Kim JS, Kim JY. Efficacy of biofeedback therapy for objective improvement of pelvic function in low anterior resection syndrome. Ann Surg Treat Res. 2019;97:194-201

25 Pourmomeny AA, Emami MH, Amooshahi M, Adibi P. Comparing the efficacy of biofeedback and balloon-assisted training in the treatment of dyssynergic defecation. Can J Gastroenterol. 2011;25:89-92

26. Lee BE, Kim GH. How to perform and interpret balloon expulsion test. J Neurogastroenterol Motil. 2014;20:407-9.

27. Carrington EV, Scott SM, Bharucha A, Mion F, Remes-Troche JM, Malcolm A, et al. Expert consensus document: advances in the evaluation of anorectal function. Nat Rev Gastroenterol Hepatol. 2018;15:309-23.

28. Rao SS, Valestin JA, Xiang X, Hamdy S, Bradley CS, Zimmerman MB. Homebased versus office-based biofeedback therapy for constipation with dyssynergic defecation: a randomised controlled trial. Lancet Gastroenterol Hepatol. 2018;3:768-77

29. Woodward S, Norton C, Chiarelli P. Biofeedback for treatment of chronic idiopathic constipation in adults. Cochrane Database Syst Rev. 2014;(3):CD008486 doi: 10.1002/14651858.CD008486.pub2.

30. Dedemadi G, Takano S. Efficacy of bilateral transcutaneous posterior tibial nerve stimulation for fecal incontinence. Perm J. 2018;22:17-231.

31. Eleouet M, Siproudhis L, Guillou N, Le Couedic J, Bouguen G, Bretagne JF. Chronic posterior tibial nerve transcutaneous electrical nerve stimulation (TENS) to treat fecal incontinence (FI). Int J Colorectal Dis. 2010;25:1127-32.

32. Ros EP, Banos PAP, Buleje JAB, Camarena JMM, Segade CE, Arenas MFC, et al. Short-term outcome of percutaneous posterior tibial nerve stimulation (PTNS) for the treatment of faecal incontinence. Tech Coloproctol. 2016;20:19-24.

33. Madbouly KM, Abbas KS, Emanuel E. Bilateral posterior tibial nerve stimulation in the treatment of rectal evacuation disorder: a preliminary report. Dis Colon Rectum. 2017;60:311-7.

34. Iqbal F, Collins B, Thomas GP, Askari A, Tan E, Nicholls RJ, et al. Bilatera transcutaneous tibial nerve stimulation for chronic constipation. Colorectal Dis. 2016;18:173-8.

35. Yik YI, Clarke MC, Catto-Smith AG, Robertson VJ, Sutcliffe JR, Chase JW, et al. Slow-transit constipation with concurrent upper gastrointestinal dysmotility and its response to transcutaneous electrical stimulation. Pediatr Surg Int. 2011;27:705-11. 